\title{
Electrocardiographic Diagnosis of Left Ventricular Hypertrophy
}

\author{
Claudio Leinig Pereira da Cunha1 ${ }^{10}$ \\ Universidade Federal do Paraná - Cardiologia, ${ }^{1}$ Curitiba, PR - Brazil \\ Short Editorial related to the article: Performance of the Electrocardiogram in the Diagnosis of Left Ventricular Hypertrophy in Older and Very \\ Older Hypertensive Patients
}

Left Ventricular Hypertrophy (LVH) is defined as an increase in left ventricular (LV) mass, which may be secondary to an increase in wall thickness (concentric LVH), increased cavity size (eccentric LVH), or both. The presentation of hypertrophied LV depends mainly on the underlying disease, with concentric $\mathrm{LVH}$ resulting in most cases from LV pressure overload (hypertension or aortic stenosis), while eccentric LVH mainly depends on LV volume overloads (mitral and aortic insufficiency) and dilated cardiomyopathies. Other causes of LVH include ventricular septal defects, hypertrophic cardiomyopathy, and physiological changes associated with athletic training. ${ }^{1}$

The presence of LVH is clinically meaningful because it is associated with an increased incidence of heart failure, ventricular arrhythmias, peripheral vascular insufficiency, aortic dilatation, cerebrovascular events and sudden death or after myocardial infarction. ${ }^{2}$

LVH can be diagnosed by electrocardiogram (ECG) or echocardiogram, which is the procedure of choice because it has a much greater sensitivity than the ECG. ${ }^{3}$ The ECG is a useful but imperfect tool in detecting LVH; its usefulness is mainly due to its low cost and universal availability, routinely performed in cardiac evaluations. Echocardiography is more expensive but not unreasonable and has also been widely available. Yet, to assess the ventricular mass, the most accessible techniques of the method are used. In few situations, cardiac magnetic resonance imaging may be necessary, only when technical conditions make echocardiographic assessment unfeasible. ${ }^{4}$

The calculation of left ventricular mass by echocardiography can be performed using different techniques - onedimensional, two-dimensional or three-dimensional, but always to quantify the myocardium in that chamber, based on common fundamentals and, therefore, with similar results. Standards of normality are recommended by the international associations of echocardiography (ASE, EACI) ${ }^{5}$ and endorsed by most authors. ${ }^{6}$ Thus, echocardiography shows uniformity of LVH results based on few studied parameters. ${ }^{5,6}$

In electrocardiography, the situation is the opposite. As early as 1969, Romhilt et al. ${ }^{7}$ described 33 electrocardiographic criteria for diagnosing LVH, and all showed low sensitivity. ${ }^{7}$ Over the years, some criteria have solidified as the most used in clinical practice for diagnosing LVH on the ECG, but there is still no consensus in this selection. In a recent article, Wang et al. ${ }^{8}$ studied the performance of seven ECG criteria in Chinese patients with LVH on echocardiography. They found a sensitivity of $15 \%-31.9 \%$ and a specificity of $91.6 \%-99.2 \%$ in the global sample, with better sensitivity in concentric $\mathrm{LVH}$. The best $\mathrm{LVH}$ descriptors in this research ${ }^{8}$ were the Sokolow-Lyon voltage, Cornell voltage, Cornell product and $\mathrm{R}$ aVL voltage criteria.

Povoa et al., ${ }^{9}$ in a publication in this journal, studied 13 electrocardiographic criteria for LVH in 2458 hypertensive patients submitted to echocardiography, classified by age group and submitted to rigorous statistical analysis. Among patients aged $\geq 80$ years, the Perugia criteria performed better (sensitivity $44.7 \%$, specificity $89.3 \%$ and DOR - diagnostic odds ratio: 6.8) and (Rmax + Smax) $x$ duration (sensitivity $39.4 \%$, specificity $91.3 \%$, DOR 6.8). In patients aged $<80$ years, in addition to these indices mentioned above, the Narita criterion, described in 2019, ${ }^{10}$ also performed well. In this research, traditional indices had lower diagnostic sensitivity: Sokolow-Lyon voltage $>35 \mathrm{~mm}$ with $12 \%-15.7 \%$ in different age groups and Cornell voltage with $17.3 \%-21 \%$ sensitivity. ${ }^{9}$

In conclusion, we understand that the electrocardiogram remains an important tool in daily cardiology practice, quite valuable when it indicates LVH, but with still modest diagnostic sensitivity, despite new research in this area.

\section{Keywords}

Hypertrophy, Left Ventriculat; Diagnostic Imaging; Electrocardiography/methods; Echocardiography/methods; Cardiomyopathy, Hypertrophic; Ventricular Dysfunction, Left. 


\section{References}

1. Levy D, Garrison RJ, Savage DD, Kannel WB, Castelli WP. Left ventricular mass and incidence of coronary heart disease in an elderly cohort. The Framingham Heart Study. Ann Intern Med.1989;110(2):101-7.

2. Eskerud I, Gerdts E, Larsen TH, Lonnebakken MT: Left ventricular hypertrophy contributes to myocardial ischemia in non-obstructive coronary artery disease (the MicroCAD study). Int J Cardiol. 2019;286:1-6.

3. Verdecchia P, Carini G, Circo A, Dovellini E, Giovannini E, Lombardo Metal. Left ventricular mass and cardiovascular morbidity in essential hypertension: the MAVI study. J Am Coll Cardiol. 2001; 38(7):1829-35.

4. Devereux RB: Is the electrocardiogram still useful for detection of left ventricular hypertrophy? Circulation. 1990;81(3):144-6.

5. Lang RM, Badano LP, Mor-Avi V, Afilalo J, Armstrong A, Ernande L, et al. Recommendations for cardiac chamber quantification by echocardiography in adults: an update from the American Society of Echocardiography and the European Association of Cardiovascular Imaging. J Am Soc Echocardogr. $2015 ; 28(1): 1-39$
6. Barberato $\mathrm{SH}$, Romano MMD, Beck ALS, Rodrigues ACT, Almeida ALC, Assunção BMBL, et al. Posicionamento sobre indicações da ecocardiografia em adultos - 2019. Arq Bras Cardiol. 2019;113(1):135-81.

7. Romhilt DW, Bove KE, Norris RJ, Conyers E, Conradi S, Rowlands DT, et al A critical appraisal of the electrocardiographic criteria for the diagnosis of left ventricular hypertrophy. Circulation. 1969; 40(2):185-95.

8. Wang D, XU JZ, Zhang W, Chen Y, Li J, An Y, et al. Performance of electrocardiographic criteria for echocardiographically diagnosed left ventricular hypertrophy in Chinese hypertensive patients. Am J Hypertens. 2020; 33(9)831-6.

9. Povoa FF, Luna-Filho B, Bianco HT, Amodeo C, Povoa R, Bombig MTN Desempenho do Eletrocardiograma no diagnóstico da hipertrofia ventricular esquerda em hipertensos idosos e muito idosos. Arq Bras Cardiol. 2021; 117(5):924-931.

10. Narita M, Yamada M, Tsuchima M,Kudo N, Kato T, Yokono Y Novel electrocardiographic criteria for the diagnosis of left ventricular hypertrophy in the Japanese general population. Int Heart J. 2019; 60(3):679-87. 